\title{
Quality of 'Brightwell' and 'Tifblue' Blueberries after Gamma Irradiation for Quarantine Treatment
}

\author{
W.R. Miller and R.E. McDonald \\ U.S. Department of Agriculture, Agricultural Research Service, U.S. \\ Horticultural Research Laboratory, 2120 Camden Road, Orlando, FL 32803
}

Additional index words. Vaccinium ashei, rabbiteye, postharvest, quality, condition

Blueberries must be subjected to a quarantine treatment of methyl bromide fumigation when shipped to certain domestic or export markets. The principle insects that inhibit distribution of blueberries are the apple maggot [Rhagoletis pomonella (Walsh)], blueberry maggot (R. mendaxCurran), and plum curculio [Conotrachelus nenuphar (Herbst)]. Methyl bromide fumigation is the only approved quarantine treatment for blueberries and it is scheduled to be phased out by the year 2001. Highbush blueberries' tolerance to low-dose irradiation is cultivar-dependent (Eaton et al., 1970). Two main cultivars grown in Florida, 'Climax' and 'Sharpblue', will tolerate irradiation up to $0.75 \mathrm{kGy}$ without loss of fruit market quality (Miller et al., 1994a, 1994b, 1995). A 1.0-kGy dose is the maximum allowed (U.S. Food and Drug Administration, 1986) for treatment of fresh fruit or vegetables, and reportedly (personal communications, J. Sharp and G. Hallman) $\approx 0.3 \mathrm{kGy}$ is sufficient for control of blueberry insects requiring quarantine certification. Two or three times the minimum dose may, however, be required to assure that the minimum dose is absorbed by all berries during commercial application. Therefore, it is most important to determine the tolerance of berries to irradiation stress. The purpose of this research was to determine the effects of low-dose irradiation on the quality and condition of 'Brightwell' and 'Tifblue', two major rabbiteye cultivars grown in Georgia. The data were subjected to analysis of variance $(P \leq 0.05)$ on a split-block experimental design, with harvest dates for 'Brightwell', and randomized sample sets as replications for 'Tifblue' berries. The data were tested for the main effect of irradiation dosage on quality attributes.

'Brightwell' berries were harvested on 15 , 19, and 22 June 1995, 'Tifblue' on 13 July from plantations near Baxley. 'Brightwell' were replicated over the three harvests, whereas 'Tifblue' berries were from a single harvest and were randomized into three replications. The same quantity of berries was tested for

Received for publication 8 June 1996. Accepted for publication 10 Aug. 1996. The cost of publishing this paper was defrayed in part by the payment of page charges. Under postal regulations, this paper therefore must be hereby marked advertisement solely to indicate this fact. both cultivars. All berries were commercially hand-harvested, hand-graded on a tilt conveyer, and packaged in $\approx 0.5$-L clear plastic clamshell baskets. After packaging, master trays (12 baskets each) were placed three each into large plastic bags, which were not closed, and placed into large Styrofoam coolers with ice and transported by auto $(\approx 5 \mathrm{~h})$ to the laboratory in Orlando. On arrival, berries were randomized into four treatments (TRT), 18 baskets each: 1) $1{ }^{\circ} \mathrm{C}$ control, 2) ambient control, 3) $0.5 \mathrm{kGy}$, and 4) $1.0 \mathrm{kGy}$. Berries from TRT 1 were placed at $1{ }^{\circ} \mathrm{C}$. The remaining berries were held overnight at $12{ }^{\circ} \mathrm{C}$ and irradiated the next morning at FOOD TECHnology Service, Mulberry, Fla. Three baskets of each treatment were evaluated after irradiation and storage for 1,3 , or 7 days at 1 ${ }^{\circ} \mathrm{C}$, plus two additional days at $15{ }^{\circ} \mathrm{C}$.

Berries were subjectively rated for firmness, decay (causal organism not identified) and juice leakage, culls (Miller and Smittle, 1987), percentage of mass loss, total soluble solids concentration (TSS), titratable acidity (citric) (TA), $\mathrm{pH}$, flavor, berry mastication texture, peel color, and powdery bloom (Miller et al., 1994a). Powdery bloom scores are index values and were assigned to baskets of berries by treatment doses. Objective firmness was determined by measuring the amount of force $(\mathrm{N})$ required to compress single berries $3 \mathrm{~mm}$ using an Instron Food Tester (model 4411; Instron Corp., Canton, Mass.) equipped with an 11-mm-diameter cylinder at a crosshead speed at $5 \mathrm{~cm} \cdot \mathrm{min}^{-1}$. Color measurements were determined using a Chroma Meter (model CR 200; Minolta, Osaka, Japan) with a 25-mm sensor set to record CIE (1976) L*, $\mathrm{a}^{*}$, and b* values. Discussion of all data is for the final results for storage of 7 days at $1{ }^{\circ} \mathrm{C}$ plus two additional days at $15^{\circ} \mathrm{C}$.

'Brightwell'. There were no significant differences in values between TRT $1\left(1{ }^{\circ} \mathrm{C}\right.$, control) and TRT 2 (ambient control) berries; therefore, only data for control ambient berries are discussed. Mean firmness of berries was $2.7 \mathrm{~N}$ with no significant differences among treatments by dose. Subjective scores indicated that $67 \%, 16 \%$, and $15 \%$ of berries were rated firm, soft, or decayed. The percentage of culls was constant among treatments (2\%). Irradiation softened berries $(72 \%, 67 \%$, and $62 \%$ firm at $0,0.5$, and $1.0 \mathrm{kGy}$, respectively) but did not affect the incidence of decay (11\% to $18 \%$ ), which was relatively high.
Mass loss averaged $2.3 \%$ and there were no differences by dose. Mean TSS and TA were $13.1 \%$ and $0.23 \%$, respectively, and were not affected by dose. Mean $\mathrm{pH}$ was 3.5 , ranging from 3.5 to 3.6, and values among doses were similar. Mean sensory flavor and texture scores were 79 and 79, respectively, and were not affected by dose. Mean $\mathrm{L}^{*}, \mathrm{a}^{*}$, and $\mathrm{b}^{*}$ color values were $29.6,0.5$, and -0.16 , respectively, regardless of doses. There was no effect of dose on powdery bloom index values, and the mean was 3.0 (100\% of surface area).

'Tifblue'. Mean objective firmness was 2.2 $\mathrm{N}$ and there was no effect of dose. Berries were subjectively rated $60 \%, 34 \%$, and $4 \%$, firm, soft, and decayed, respectively. There were no differences among doses for any attribute indicated. Mass loss over all treatments averaged $2 \%$. TSS and TA averaged $15.5 \%$ and $0.25 \%$, and $\mathrm{pH}$ was 3.4 . Sensory flavor and texture values averaged 71 and 67 . Color values for $\mathrm{L}^{*}, \mathrm{~b}^{*}$ and $\mathrm{a}^{*}$ were $30.9,0.6$, and -0.5 , respectively, and the powdery bloom index was also 3.0, regardless of dose.

'Brightwell' and 'Tifblue' berries tolerated low-dose irradiation at levels above those required for commercial application of quarantine disinfestation. Our findings indicate that the responses of these two cultivars to irradiation treatment and storage are generally consistent with those for 'Climax' (Miller et al., 1994b) and 'Sharpblue' (Miller et al., 1995). 'Brightwell' berries had a shorter shelflife, primarily due to a high incidence of decay compared with other cultivars we have tested. Although irradiation did not have a significant negative impact on flavor and texture preferences, there was a trend for 'Brightwell' quality to decline as dosage increased. When the U.S. Dept. of Agriculture Animal and Plant Health Inspection Service approves irradiation for quarantine certification, 0.5 to $1.0 \mathrm{kGy}$ likely will be a viable treatment available for industry usage on major blueberry cultivars grown in the southeastern United States.

\section{Literature Cited}

Eaton, G.W., C. Meehan, and N. Turner. 1970. Some physical effects of postharvest gamma radiation on the fruit of sweet cherry, blueberry, and cranberry. J. Can. Inst. Food Sci. Technol. 3:152-156.

Miller, W.R., R.E. McDonald, T.G. McCollum, and B.J. Smittle. 1994a. Quality of 'Climax' blueberries after low dosage electron beam irradiation. J. Food Quality 17:71-79.

Miller, W.R., R.E. McDonald, and B.J. Smittle. 1995. Quality of 'Sharpblue' blueberries after electron beam irradiation. HortScience 30:306308.

Miller, W.R., E.J. Mitcham, R.E. McDonald, and J.R. King. 1994b. Postharvest storage quality of gamma-irradiated 'Climax' rabbiteye blueberries. HortScience 29:98-101.

Miller, W.R. and D.A. Smittle. 1987. Storage quality of hand- and machine-harvested rabbiteye blueberries. J. Amer. Soc. Hort. Sci. 112:487490.

U.S. Food and Drug Administration. 1986. Irradiation in the production, processing, and handling of foods: Final rules. Federal Register 51:1337513339 . 